\title{
BMD status of Postmenopausal Women in relation with BMI: A study with 93 cases
}

Samira Sharmin, Mabubul Haque, Syedur Rahman Miah, Md. Mahbub ur Rahman, Jasmine Ara Haque, Hosne Ara Rahman, Md. Abu Bakker Siddique, Jasmine Ferdous, Md. Monir Uddin, Farida Yeasmin

\author{
Institute of Nuclear Medicine and Allied Sciences, Mitford, Dhaka
}

Address for correspondence: Dr. Samira Sharmin, Senior Medical Officer. Institute of Nuclear Medicine and Allied Sciences, Sir Salimullah Medical College Campus, Mitford, Dhaka. E-mail: samira958@gmail.com

\section{ABSTRACT}

Objectives: Low bone mass is a common disorder in elderly population which predisposes to fracture with minimal trauma. This study was performed to find out the association between the Body Mass Index (BMI) and Bone Mineral Density (BMD) in postmenopausal women.

Materials and Methods: This cross sectional study was carried out at Institute of Nuclear Medicine and Allied Sciences Comilla and Mitford, Dhaka over a period of 12 months from January 2013 to December 2013. A total 93 postmenopausal women were enrolled for this study. All postmenopausal women underwent a BMD scan of femoral neck and lumbar vertebrae using a Dual Energy X-ray Absorptiometry (DEXA). Participants were categorized into three groups according to their age and BMI. BMD were expressed base on T-score according to $\mathrm{WHO}$ criteria. The relation among BMI, age and BMD were assessed.

Results: The results of this study showed that the mean age of the study group was $57.13 \pm 7.49$ years with range of 46 to 75 years. The most postmenopausal women were in age group 55-65years. The mean BMI of the study subjects were $24.18 \pm 5.08 \mathrm{~kg} / \mathrm{m}^{2}$ with a range of 15.62 to $36.20 \mathrm{~kg} / \mathrm{m}^{2}$. Among 93 subjects osteopenia was greater at lumbar spine (45.2\%) with $\mathrm{T}$-score mean \pm SD-1.83 \pm 0.33 and osteoporosis at femoral neck $(51.6 \%)$ with $\mathrm{T}$-score mean \pm SD-3.36 \pm 0.67. Pearson's correlation coefficient test showed inverse relationship between age and BMD both lumbar spine ( $r=$ $\mathbf{- 0 . 3 0 1}, p=0.003)$ and femoral neck $(r=-0.303, p=0.003)$ whereas the positive relation between BMI and BMD both at lumbar spine $(r=0.338, p=0.001)$ and femoral neck ( $r$ $=0.343, p=0.001)$. These showed that with advancing age, BMD decreases and the risk of osteoporosis increases and with increasing BMI, BMD increases and risk of osteoporosis decreases.

Conclusion: The findings of this study portrait that aging and low BMI are risk factors associated with bone loss. So preventive measure should be taken for high risk post menopausal women.
Keywords: Body Mass Index (BMI), Bone Mineral Density (BMD), Postmenopausal women.

\section{INTRODUCTION}

Menopause is applied to women who have not experienced menstrual bleed for a minimum of 12 months, assuming that they do still have a uterus and are not pregnant or lactating (1). Women all over the world now have to spend almost one third of their lives in menopause years as because average life expectancy is increasing (2). Average life expectancy for Bangladeshi women is 72 years (3), with an average age for menopause being 46 51 years (4). It is well established from many studies that the metabolic changes occurred during menopause is not only due to hormonal changes but aging also plays a role (5). Body Mass Index (BMI) is the measure of human body shape based on an individual mass and height. According to World Health Organization (WHO), the normal BMI range is between 18.50-24.99 kg/m² (6). Bone Mineral Density (BMD) is a measure of calcium and other minerals in the bone, which gives it strength (2). During menopause, bone resoprtion exceeds formation, producing a negative balance resulting bone loss. Approximately $35 \%$ of postmenopausal women loses significant amount of bone mineral density during this period (7). In Bangladesh like other developing countries poverty, ignorance and social factors play negative role on food intake of women, they eat last and least (8). For these reasons in our country postmenopausal women may suffer from low bone mass, leading to osteoporosis and osteoporosis related facture. 


\section{MATERIALS AND METHODS}

This analytical cross sectional study was carried out at the Institute of Nuclear Medicine and Allied Sciences, Comilla and Mitford, Dhaka, over a period of 12 months from January 2013 to December 2013. A total 93 postmenopausal women were included in this study age between 46 to 75 years. The sampling method was convenience and purposive. The postmenopausal women with co-morbidities like CKD, COPD, CLD and parathyroid disorder, thyroid disorder, taking hormone replacement therapy, surgical menopause were excluded from the study. Each of the study subjects underwent Dual Energy X-ray Absorptiometry (DEXA) of both femoral neck and lumbar vertebrae. World Health Organization (WHO) criteria of osteoporosis (based on T-score) were use to assess the BMD status of the study subjects. Here normal BMD categorized as Tscore $\geq-1$, low bone mass (osteopenia) as T-score <1and $>-2.5$, osteoporosis as $\mathrm{T}$-score $\leq-2.5$. There after statistical analysis such as Chi-square test, Pearson's correlation coefficient was performed to find out the association between two variables age and BMI with BMD. In each analysis, $\mathrm{P}$ value $\leq 0.05$ was considered as statistically significant.

\section{RESULTS}

Among 93 study subjects, there were 52(55.9\%) in age group $\leq 55$ years, $27(29 \%)$ in age group 55-65 years and $14(15.1 \%)$ in age group $>65$ years. The mean \pm SD was $57.13 \pm 7.49$ with a range of 4675years.The distribution of BMI among study subjects showed that among participants 42 (45.2\%) were overweight, 32 (34.4\%) had normal BMI and rest of $19(20.4 \%)$ were underweight. The mean \pm $\mathrm{SD}$ was $24.18 \pm 5.08 \mathrm{~kg} / \mathrm{m}^{2}$ with a range of 15.62 $36.20 \mathrm{~kg} / \mathrm{m}^{2}$.

The frequency and percentage of low BMD in terms of osteopenia, osteoporosis and normal BMD at lumbar spine showed that majority $80(80.1 \%)$ of women had normal BMD and rest 13 (14\%) of them had low BMD. Among low BMD group 35 (40.9\%) women were osteoporosis with $\mathrm{T}$ - score mean $\pm \mathrm{SD}$ $3.16 \pm 0.57$ and $42(45.2 \%)$ were osteopenic with $\mathrm{T}$ score mean $\pm \mathrm{SD}-1.83 \pm 0.33$. The frequency and percentage of low BMD (osteoporosis and osteopenia) and normal BMD value at femoral neck showed that $12(12.9 \%)$ had normal BMD and rest $81(87.1 \%)$ had low BMD level. 48 ( 51.6\%) women were osteoporotic with mean \pm SD-3.36 \pm 0.67 and $33(33.5 \%)$ were osteopenic with mean \pm SD $-1.86 \pm$ 0.38 .

Relationship between age and BMD at lumbar spine showed that among normal BMD group, $8(15.4 \%)$ were in age group $\leq 55$ years, $4(14.8 \%)$ were in age group 55-65 years and $1(7.1 \%)$ was in age group >65 years. Among participants majority had osteopenia $30(57.7 \%)$ in age group $\leq 55$ years and $16(59.3 \%)$ women had osteoporosis in age group 55-65 years. These results were statistically significant ( $\mathrm{P}$ value < 0.005). Relationship between age and BMD at femoral neck showed that no women had normal BMD value in age group >65 years and $3(11.1 \%)$ had normal BMD value in age group 55-65 years and $9(17.3 \%)$ had normal BMD value in age group $\leq 55$ years. In case of $>65$ years age group, $10(71.4 \%)$ were osteoporotic. These results were not statistically significant $(\mathrm{P}>0.05)$.

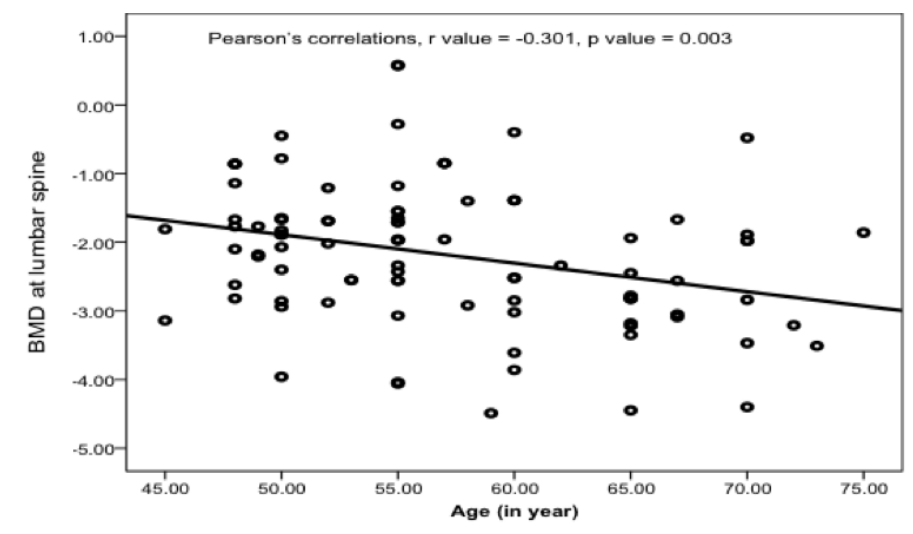

Figure1: Correlation of BMD at lumbar spine with age showing negative relation

The Pearson's correlation test showed negative correlation relation both at femoral neck $(\mathrm{r}=$ $0.303, \mathrm{p}=0.003)$ and lumbar spine $(\mathrm{r}=-0.301$, $\mathrm{p}=0.003$ ) with age. 
Relationship between BMI and BMD at lumbar spine showed that in underweight group no one had normal BMD value, 2(6.3\%) had normal BMD value in normal BMI group and large percentage women $11(26.2 \%)$ had normal BMD value in overweight group. In case of underweight group, 11 (57.9\%) were osteopenic and 8(42.1\%)were osteoporotic. The results were statistically significant $(\mathrm{P}<0.05)$.

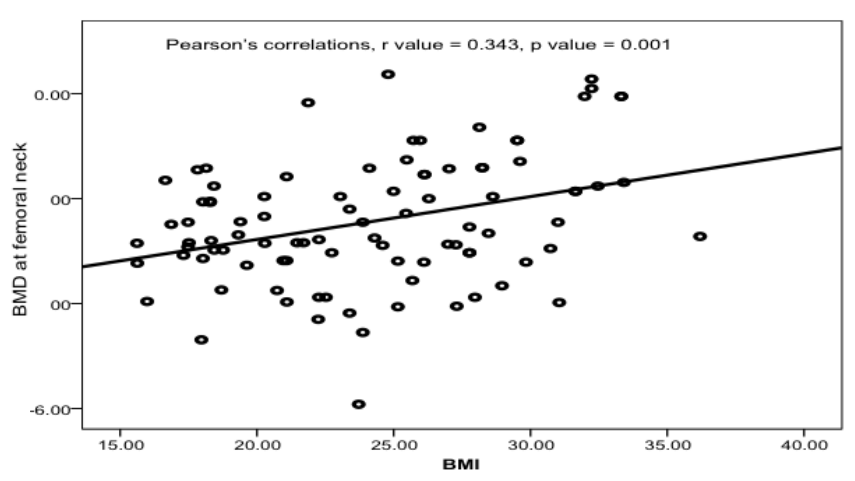

Figure 2: Correlation of BMD at femoral neck with BMI showing positive relation

Pearson's correlation coefficient test showed that positive relationship between BMI and BMD at lumbar spine $(\mathrm{r}=0.338 . \mathrm{p}=0.001)$ as well as femoral neck $(\mathrm{r}=0.343, \mathrm{p}=0.001)$.

\section{DISCUSSION}

Low bone mass (osteoporosis and osteopenia) is a significant risk factor for morbidity and mortality in postmenopausal women worldwide not only in developed countries but also in developing countries like Bangladesh (8). BMD test is used to assess the strength of bone whereas BMI indicate the nutritional status of a person $(9,10)$. When considering the BMI, weight and BMD values are positively correlated in both young and old age $(8,9)$.

In our study, regarding BMI 45.2\% was overweight, $20.4 \%$ were underweight and rests had normal BMI. Regarding BMD at femoral neck (51.6\%) was osteoporotic and $35.5 \%$ were osteopenic with prevalence of osteopenia more among the age group $\leq 55$ years.
Relation between age and BMD at lumbar spine was that $57.1 \%$ of the study subjects were osteoporotic in age group > 65yeras, but only $26.9 \%$ were osteoporotic in age group $\leq 55$ years. In case of BMD at femoral neck $71.1 \%$ were osteoporotic in age group > 65yearss whereas 44.2 $\%$ were osteoprotic. Findings of this study were very much consistent with earlier studies $(9,10)$.

In the present study, the negative effect of age was observed on BMD at lumbar spine ( $\mathrm{r}=-0.301$ and $\mathrm{p}=0.0003)$ and femoral neck $(\mathrm{r}=0.303$ and $\mathrm{p}=$ 0.0003). Very much similar findings were observed in previous different studies. Study subjects of all those studies had low bone mass with advancing age $(7,8)$. The age related decline of muscle strength and ovarian estrogen production may be responsible for low bone mass in those women $(2,9)$. From above findings it can be concluded that advancing age associated with lower BMD.

In the present study association between BMI and BMD showed that, in underweight group, all were osteoporotic and osteopenic $(42.1 \%$ and $57.9 \%$ respectively at lumbar spine, $52.6 \%$ and $47.4 \%$ respectively at femoral neck). Nihal et al. also showed the similar findings that lower BMI was associated with lower BMD (1). In this study it was also noticed that no one had normal BMD value at lumbar or femoral neck in underweight group. On the other hand in over weight group the number of normal BMD value was $26.2 \%$ at lumbar spine and $23.8 \%$ was at femoral neck. These differences were statistically significant $(\mathrm{P}<0.05)$. These findings were similar with those previous studies that reported that increased BMD in over weight group may be due to the secretion of active bone hormones from pancreatic beta cell (insulin, amylin and preptin) and secretion of bone active hormones such as estrogen and leptin from adipocytes $(7,9)$. 
Statistically positive correlation of BMI with BMD was found both in lumbar spine $(\mathrm{r}=0.338, \mathrm{p}=$ $0.001)$ and femoral neck $(r=0.304, p=0.001)$. Findings of this study are similar with that of the previous studies $(7,8,9,10)$. This positive correlation between overweight and bone mass could be due to the influence of estrone and mechanical load on skeleton $(1,2,7)$.

\section{CONCLUSION}

The results of this study showed that BMI is positively correlated with BMD whereas as age is negatively correlated with BMD. It can be conclude that high BMI is a protective measure against osteoporosis. So these findings highlight the need for early identification of high-risk postmenopausal women so that early intervention measure could be taken.

\section{REFERENCES}

1. Nihal S, Fatima SS, Abbass K, Memon AS. Association of body mass index and bone mineral density in pre and post menopausal women of Karachi. Medical Journal 2012:2; 446-450.

2. Oros S, I anas O, Valdoius S, Giurcaneanu M, Ionescu L, Neacsu E et al. Does obesity protect postmenopausal women against osteoporosis. Acta Endocrinologica 2012; 2: 446-450.

3. World Health Organization-NCD Countries profile, $2011 \quad$ Bangladesh. www.who.int/countries/bdg/en)

4. Handa R, Kalla AA, Maalouf G. Osteoporosis in developing countries. Best practice \& research clinical rheumatology 2008; 22:4:693708.

5. Jesmin $\mathrm{S}$, Islam $\mathrm{A} M \mathrm{~S}$, Akther $\mathrm{S}$ et al. Metabolic syndrome among pre and post menopausalrural women in Bangladesh: result from a population based study. BMC research 2012; 6: 157.

6. World Health Organization-Obesity: Preventing and managing the global epidemic: WHO Technical reports series 2000:894.
7. Ahlborg HG, Johnell O, Turner CH, Rannevik $\mathrm{G}$, Karlsson. Bone loss and bone size after menopause The New England Journal of Medicine 2003:349;4;327-34.

8. Chowdhury S, Ashrafunnessa, Khatun S, Sarker NR. Comparison of bone mineral density between premenopausal and postmenopausal women in Bangladesh. Bangladesh Medical Res Council Bulletin 2001; 27:2: 48-54.

9. Lane NE. Epidemiology, etiology and diagnosis of osteoporosis 2006:194.

10. Hussain R. Obesity as a safety factor in osteoporosis- DEXA study in postmenopausal Women. Bangladesh JNM 2005; 2:2:84-86. 